\title{
Nitric Oxide Metabolites as Biomarkers for Influenza-Like Acute Respiratory Infections Presenting to the Emergency Room
}

\author{
Asad I. Mian ${ }^{*}, 1$, Federico R. Laham ${ }^{2, \#}$, Andrea T. Cruz ${ }^{1,2}$, Harsha Garg ${ }^{3}$, \\ Charles G. Macias ${ }^{1}$, A. Chantal Caviness ${ }^{1}$ and Pedro A. Piedra ${ }^{2,4}$
}

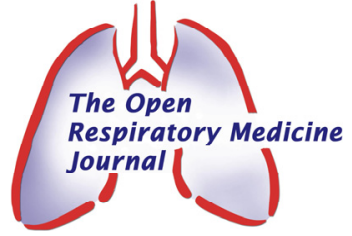

${ }^{I}$ Dept of Pediatrics, Section of Emergency Medicine, Texas Children's Hospital, Baylor College of Medicine, Houston TX 77030, USA

${ }^{2}$ Dept. of Pediatrics, Section of Infectious Diseases, Texas Children's Hospital, Baylor College of Medicine, Houston TX 77030, USA

${ }^{3}$ Brown Foundation Institute of Molecular Medicine, University of Texas - Houston Health Science Center, Houston TX 77030, USA

${ }^{4}$ Molecular Virology \& Microbiology, Baylor College of Medicine, Houston TX 77030, USA

\begin{abstract}
Aims: Nitric oxide (NO) is increased in the respiratory tract in pulmonary infections. The aim was to determine whether nasal wash NO metabolites could serve as biomarkers of viral pathogen and disease severity in children with influenza-like illness (ILI) presenting to the emergency department (ED) during the 2009 influenza A H1N1 pandemic.

Methods: Children $\leq 18$ years old presenting to the ED with ILI were eligible. Nasal wash specimens were tested for NO metabolites, nitrate and nitrite, by HPLC and for respiratory viruses by real-time PCR.

Results: Eighty-nine patients with ILI were prospectively enrolled during Oct-Dec, 2009. In the entire cohort, nasal wash nitrite was low to undetectable (interquartile range [IQR], $0-2 \mu \mathrm{M}$ ), while median nitrate was $3.4 \mu \mathrm{M}$ (IQR 0-8.6). Rhinovirus (23\%), respiratory syncytial virus (RSV) (20\%), novel H1N1 (19\%), and adenovirus (11\%) were the most common viruses found. Children with RSV subtype B-associated ILI had higher nitrate compared to all other viruses combined $(P=0.002)$.

Conclusion: Concentration of NO-derived nitrate in nasal secretions in children in the ED is suggestive of viral pathogen causative for ILI, and thus might be of clinical utility. Predictive potential of this putative biomarker for ILI needs further evaluation in sicker patients in a prospective manner.
\end{abstract}

Keywords: Acute respiratory infections, emergency department, nitrate, Novel H1N1, pediatrics, RSV.

\section{INTRODUCTION}

Pandemics like the 2009 novel swine-origin influenza A (H1N1) virus (nH1N1) pose significant challenges: increased transmission relative to seasonal influenza [1], severe disease in patients with medical co-morbidities [1], and difficulty in predicting which children with viral respiratory symptoms are at risk for influenza complications. In the evaluation of acutely ill children in emergency department (ED) settings, risk stratification may be achieved by utilizing biomarkers, augmenting clinical decision-making, thus improving outcomes.

\footnotetext{
*Address correspondence to this author at the Dept. of Pediatrics, Section of Emergency Medicine, Texas Children's Hospital, Baylor College of Medicine, 1102 Bates Street, FC 1850.00, Houston, TX. 77030, USA; Tel: 832-824-5497; Fax: 832-825-1181; E-mail: amian@bcm.edu
}

${ }^{\#}$ Current affiliation: Pediatric Infectious Diseases Practice, Arnold Palmer Hospital for Children, Orlando FL 32806, USA
During influenza virus infection, epithelial cells, macrophages, lymphocytes and other cells release a complex series of cytokines and chemokines in an attempt to overcome viral replication and disease progression [2-4]. Nitric oxide (NO) [5-8], a key mediator of airway inflammation [9], is also released. It is unclear if increased NO activity is a marker of clinical disease, of the innate antiviral response, or associated significantly with a unique respiratory virus infection. In the murine model of respiratory syncytial virus (RSV) for instance, NO production in the lungs appears to be associated with viral clearance and lung disease [5]. Inducible nitric oxide synthase (iNOS) activity and production of NO was associated with enhanced clearance of RSV, yet they were also associated with airway inflammatory changes and airway dysfunction [5]. In murine studies of experimental influenza A-triggered pneumonia, excessive NO biosynthesis, as measured by its metabolites nitrate and nitrite, was demonstrated in the lungs [6,7]. This suggested that the metabolites may be markers of influenza-mediated disease in the respiratory tract. In humans, NO is produced in 
the upper and lower respiratory tract. It can be detected in exhaled air of healthy individuals and at increased levels in subjects with pulmonary disease, including asthma, bronchiectasis and upper respiratory infections [10-14]. In aqueous solutions, $\mathrm{NO}$ is rapidly converted to distinct oxides of nitrogen $[10,15]$, which may thus be potential biomarkers of disease severity in acutely ill children presenting with influenza-like-illness (ILI).

We conducted this as a pilot study to test the hypothesis that concentration of NO metabolites, nitrite and nitrate, in respiratory secretions would be dependent on type of viral pathogen and severity of illness. Our primary objective was to describe stable nitrate and nitrite in nasal wash secretions as potential indicators of viral pathogen causative of the ILI in children who presented to the pediatric ED during the 2009 nH1N1 pandemic. Our secondary objective was to determine if NO metabolites in nasal wash secretions were predictive of disease severity.

\section{MATERIAL AND METHODS}

\subsection{Study Design/Patient Enrollment}

We performed a cross-sectional single-center convenience study evaluating nasal wash (NW) nitrate and nitrite in children $0-18$ years of age presenting to the emergency department (ED) of Texas Children's Hospital (Houston, TX) with ILI from October 1-December 31, 2009. Patients were included if they had an ILI (met the Centers for Disease Control and Prevention case definition for ILI [16]) or a positive point-of-care test for influenza. The study period overlapped part of the $2009 \mathrm{nH} 1 \mathrm{~N} 1$ and RSV outbreaks in Houston. Institutional review board approval was obtained prior to study initiation (IRB\#H-25083). After informed consent, clinical data were entered into standard case reporting forms. These included patient age, gender, ethnicity, medical history, vital signs, and physical examination findings. A nasal wash sample was also collected.

\subsection{Nasal Wash Collection and Processing/Storage}

During the child's visit to the ED, a nasal wash (NW) sample was collected by a standardized method previously described by our team [17]. We instilled $2 \mathrm{~mL}$ of normal saline into one of the external nares. A flexible rubber tube was then utilized to aspirate the material back into a syringe containing $2 \mathrm{~mL}$ of normal saline. This was repeated in the other naris, and the samples pooled. One $\mathrm{ml}$ of $\mathrm{NW}$ was transferred to a cryovial and rapidly frozen to $-20^{\circ} \mathrm{C}$, and later analyzed for NOx (see below). The remaining nasal wash was added to transport medium with a virus stabilizer (15\% glycerol in Iscove's media), in a 1:1 dilution. This was refrigerated at $4{ }^{\circ} \mathrm{C}$ for no longer than $72 \mathrm{~h}$. It was then processed for viral isolation as described below (see also ref. $[17,22])$.

\subsection{Viral Diagnostics}

Viral detection was performed by real-time PCR for a panel of respiratory viral pathogens that included $\mathrm{nH} 1 \mathrm{~N} 1$, seasonal influenza A (H1N1) virus, parainfluenza virus 1, RSV-A and RSV-B, human rhinovirus (HRV), adenovirus, enterovirus and human metapneumovirus.

\subsection{Nasal Wash Nitrate and Nitrite Assessment}

Nasal wash NOx (combined nitrate and nitrite) analysis was performed in the laboratory of Dr. Nathan Bryan. After thawing an aliquot of nasal secretion, NOx analysis was conducted by a dedicated ENO-20 HPLC System (EiCom Corporation) [18]. This system is sensitive and selective for the measurement of nitrate and nitrite in all biological matrices and has the capacity for high throughput (lower limit of detection is $0.1 \mathrm{pmol}$ at $100 \mu 1$ of sample injection). The ENO-20's high sensitivity is attained by the combination of a diazo coupling technique with the extract to be measured and separation of nitrite and then nitrate using a reverse-phase column. To separate nitrite and nitrate, the nitrate was first reduced to nitrite through a reaction with cadmium and reduced copper inside a reduction column. The two resolved peaks were then mixed with Griess reagent (dinitrogen trioxide, $\mathrm{N}_{2} \mathrm{O}_{3}$, generated from acidified nitrite that reacts with sulfanilamide) in-line to form the classical diazo compound which was then detected spectrophotometrically. Triplicate determinations were performed on each specimen and the final values averaged.

\subsection{Detection of IgA and IgG Immunoglobulins in Nasal Wash}

Prior to initiating the study, personnel were trained in a standardized nasal wash collection method we previously used in a bronchiolitis study conducted in the ED [17, 22]. Unlike the previous clinical study, multiple persons were involved in the collection of nasal wash specimens in the current study. Also consistent with the prior bronchiolitis study, the nasal wash specimens were diluted up to eightfolds to ensure adequate volume to conduct the planned assays. We used the detection of $\operatorname{IgA}$ and $\operatorname{IgG}$ immunoglobulins in the nasal wash specimen as markers of a "good quality" specimen. Capture ELISA assays specific for IgA and IgG immunoglobulins were performed as previously described from this laboratory [23]. A $1 / 32$ dilution in duplicate of each nasal wash specimen was tested for IgA and IgG immunoglobulins. The lower limit of detection for the diluted nasal wash specimen was approximately $60 \mathrm{ng} / \mathrm{ml}$ for total $\mathrm{IgA}$ and $114 \mathrm{ng} / \mathrm{ml}$ for total IgG. The detection of either $\operatorname{IgA}$ or $\operatorname{IgG}$ immunoglobulin indicated the specimen was of "good quality". In general, all nasal wash specimens with detectable $\operatorname{IgA}$ also had detectable $\operatorname{IgG}$ immunoglobulin except for one specimen that only had detectable IgA immunoglobulin.

\subsection{Statistical Analysis}

Stata Version 10 (Stata, Inc., College Station, TX) was used for statistical analyses. Patient demographic characteristics were described using frequencies for categorical variables and measures of central tendency and dispersion for continuous variables. Distributions were explored for NW nitrite and nitrate concentrations; all were found to be non-Gaussian in distribution; as such, nonparametric tests were used (Kruskal-Wallis test for multiple groups and Mann-Whitney U test for two groups) to make statistical comparisons across groups. $P$ values less than 0.05 were considered statistically significant. Comparisons were made across groups with nH1N1 infection, non-nH1N1 viral infection, and no viral infection detected as well as across groups with a single viral infection, co-viral infections, and no viral infection detected. We also statistically explored if 
NW nitrate level was higher in children with more severe ILI. When estimates were calculated for all samples (overall), a value of zero was assigned to each undetectable nitrate value. Therefore, zero values were part of the parameter estimation and statistical comparisons for these samples. When estimates were calculated for samples with detectable nitrate, a missing value was assigned to each undetectable nitrate sample. Therefore, undetectable samples were excluded from parameter estimation and statistical comparisons.

\section{RESULTS}

\subsection{Demographics/Clinical Follow-Up}

A nasal wash specimen was collected on 88 of the 89 subjects enrolled. Median age was 1.7 years (range 1 mo-
$18 y) ; 44 \%$ were male, $68 \%$ were Hispanic. Sixteen patients $(18 \%)$ were hospitalized. The median hospital length of stay was 2 days (range 1 to 6 days). Only 1 patient was admitted to the intensive care unit during hospitalization. Six patients (7\%) required oxygen but none were intubated. Age, gender, ethnicity, and clinical outcomes, including hospitalization, supplemental oxygenation and intravenous fluid usage, were compared between subjects with ILI infected with $\mathrm{nH} 1 \mathrm{~N} 1$, non-nH1N1viruses, or no virus detected: no significant differences were found (Table 1).

\subsection{Virologic Results}

A virologic diagnosis was obtained in $60(68 \%)$ of 88 patients with ILI presenting to the ED. HRV ( $n=20 ; 23 \%)$, RSV $(n=18 ; 20 \%), n H 1 N 1(n=17 ; 19 \%)$, and adenovirus $(n=10 ; 11 \%)$ were the most commonly detected viruses. Co-

Table 1. Demographic Characteristics, Clinical Outcomes and Nasal Wash Nitrate Between Subjects with ILI Infected with Novel (n) H1N1, Non-nH1N1 Viruses or No Virus Detected, at the TCH ED During the 2009 nH1N1 Pandemic

\begin{tabular}{|c|c|c|c|c|c|}
\hline & $\begin{array}{c}\text { Total } \\
\mathbf{N}=\mathbf{8 8} \\
(\%)\end{array}$ & $\begin{array}{l}\text { nH1N1 Virus } \\
\text { Positive Group } \\
\text { n=17 (\%) }\end{array}$ & $\begin{array}{l}\text { Non-nH1N1 Virus } \\
\text { Positive Group } \\
\text { n=43(\%) }\end{array}$ & $\begin{array}{c}\text { No Vírus } \\
\text { Detected } \\
\text { Group } \mathbf{n = 2 8 ( \% )}\end{array}$ & P-Value \\
\hline Age in Months: Median (IQR) & $20(6-57)$ & $59(7-85)$ & $11(5-22)$ & $33(11-84)$ & $0.002 *$ \\
\hline Gender & & & & & $0.415^{* *}$ \\
\hline Male & $39(44 \%)$ & $9(53 \%)$ & $16(37 \%)$ & $14(50 \%)$ & \\
\hline Female & $49(56 \%)$ & $8(47 \%)$ & $27(63 \%)$ & $14(50 \%)$ & \\
\hline Ethnicity/Race & & & & & $0.051 * *$ \\
\hline Hispanic & $60(68 \%)$ & $15(88 \%)$ & $30(70 \%)$ & $15(54 \%)$ & \\
\hline Non-Hispanic & $28(32 \%)$ & $2(12 \%)$ & $13(30 \%)$ & $13(46 \%)$ & \\
\hline Black & 2 & 0 & 2 & 0 & \\
\hline White & 15 & 1 & 6 & 8 & \\
\hline Asian & 11 & 1 & 5 & 5 & \\
\hline \multicolumn{6}{|l|}{ Clinical Outcomes } \\
\hline Hospitalized & $16(18 \%)$ & $2(12 \%)$ & $10(23 \%)$ & $4(14 \%)$ & $0.472 * *$ \\
\hline Hours in ED: Median (IQR) ${ }^{+}$ & $3.6(2.3-5.1)$ & $3.5(2.0-5.1)$ & $3.5(2.6-5.3)$ & $4.1(1.9-5.1)$ & $0.873 *$ \\
\hline Supplemental Oxygen & $6(7 \%)$ & $0(0 \%)$ & $4(9 \%)$ & $2(7 \%)$ & $0.435 * *$ \\
\hline Hours of Oxygen: Median (IQR) & $34(12-55)$ & NA & $42(31-79)$ & NA & $0.064 *$ \\
\hline Intravenous Fluids (IVF) & $14(16 \%)$ & $1(6 \%)$ & $8(19 \%)$ & $5(18 \%)$ & $0.451 * *$ \\
\hline Hours of IVF: Median (IQR) & $21(5-40)$ & NA & $33(19-41)$ & $9(3-18)$ & $0.057^{*}$ \\
\hline Healthcare visit after discharge & $18(21 \%)$ & $5(29 \%)$ & $6(15 \%)$ & $7(26 \%)$ & $0.377 * *$ \\
\hline \multicolumn{6}{|l|}{ Nasal Wash Nitrate $(\mu \mathrm{M})$} \\
\hline Median (IQR) Nitrate (overall) & $3.4(0.0-8.6)$ & $2.2(0.0-10.8)$ & $4.7(0.2-11.5)$ & $1.6(0.0-4.9)$ & $0.076^{*}$ \\
\hline Nitrate Detectable & & & & & $0.647 * *$ \\
\hline Nitrate Undetectable & $26(30 \%)$ & $6(35 \%)$ & $10(23 \%)$ & $10(36 \%)$ & \\
\hline Missing & $1(2 \%)$ & $0(0 \%)$ & $1(2 \%)$ & $0(0 \%)$ & \\
\hline Nitrate Detectable & $61(69 \%)$ & $11(65 \%)$ & $32(74 \%)$ & $18(64 \%)$ & \\
\hline Median (IQR) Nitrate (when Detected) & $5.3(3.0-11.3)$ & $5.3(2.2-13.5)$ & $7.5(3.6-14.4)$ & $4.3(1.7-5.6)$ & $0.061^{*}$ \\
\hline Nasal Wash IgA Detected & $61(69 \%)$ & $11(65 \%)$ & $39(91 \%)$ & $11(39 \%)$ & $<0.0001 * *$ \\
\hline
\end{tabular}

${ }^{*}$ Most common viruses identified were rhinovirus, RSV and adenovirus.

${ }^{+}$For patients discharged home from the ED.

*Kruskal-Wallis Test; ** Chi-Square Test. 
Table 2. Demographics, Clinical Outcomes and Nasal Wash Nitrate Compared Between Subjects with ILI Infected with Single Virus, Co-Viruses and those with No Virus Detected, at the TCH ED During the 2009 nH1N1 Pandemic

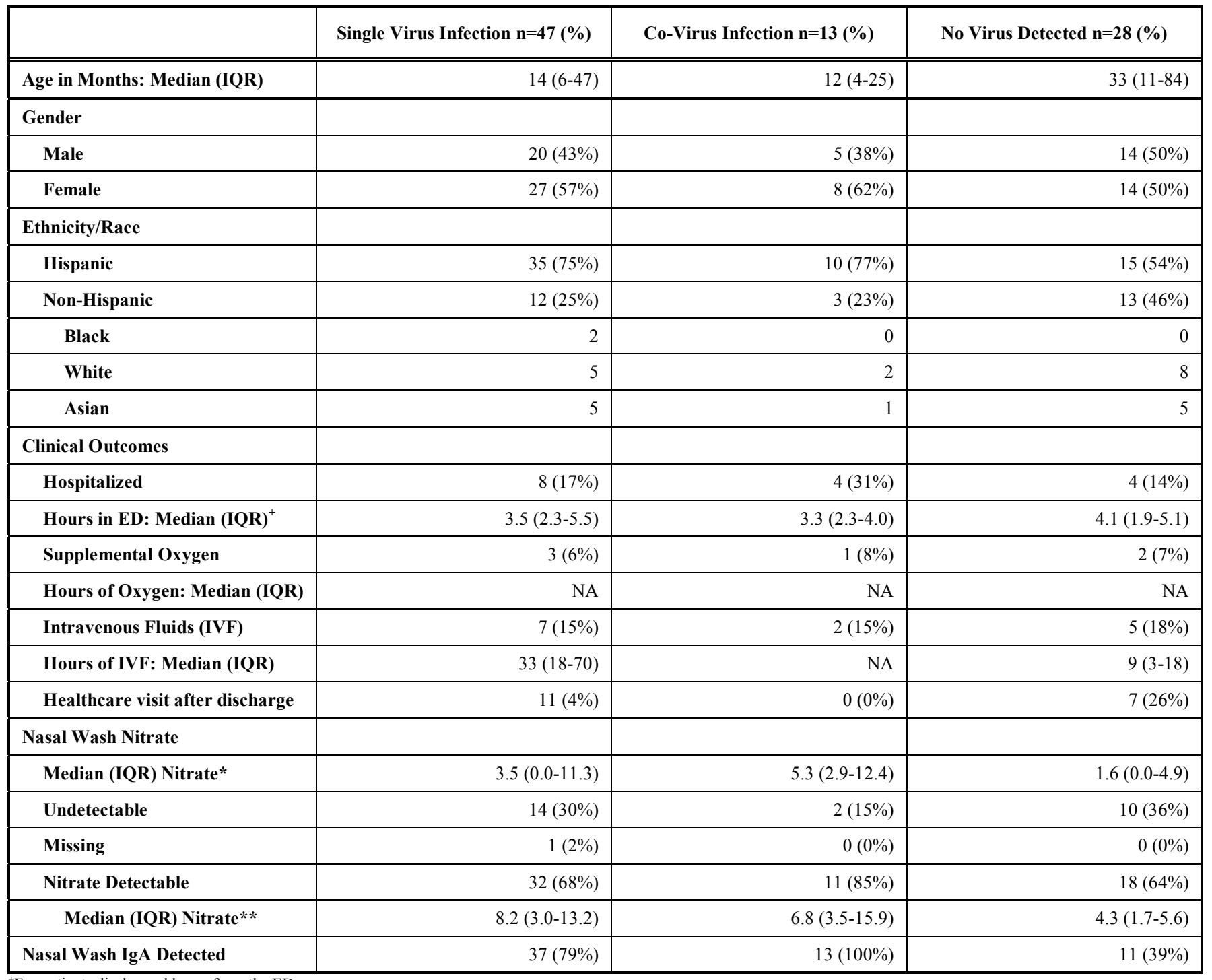

${ }^{+}$For patients discharged home from the ED.

*For all samples ( $\mathrm{p}=0.079$ by Kruskal-Wallis Test).

** For samples with detectable nitrate ( $\mathrm{p}=0.070$ by Kruskal-Wallis Test).

infections were observed in $22 \%$ of those with any virologic diagnosis obtained; $32 \%$ had no virus detected. Demographic features and clinical outcomes when comparing children with ILI due to single viral infections, co-infections or those with no virus detected are presented in Table 2: no significant differences were found.

\subsection{Nasal Wash Nitrite and Nitrate Results}

Nasal wash nitrite level was low in the children enrolled in our study (range 0.001-2 $\mu \mathrm{M}$ ). Nasal wash nitrite concentration in children with ILI was not significantly different between the children infected with $\mathrm{nH} 1 \mathrm{~N} 1$, nonnH1N1 virus and no virus detected (data not shown).

Overall, median nitrate concentration was $3.4 \mu \mathrm{M}$; interquartile range (IQR) 0-8.6. Table 1 compares NW nitrate concentration between $\mathrm{nH} 1 \mathrm{~N} 1$ virus positive, nonnH1N1 virus positive and no virus detected groups. Significant difference in the NW nitrate concentration was not observed between the groups. The levels were comparable between the groups when only those specimens were analyzed in which nitrate was detectable (Table 1).

We were interested in conducting exploratory analysis with RSV because of the higher NW nitrate level observed with single infections. An ad hoc analysis demonstrated that RSV-B infection was associated with significantly higher nitrate levels, when compared against non-RSV-B infections $(p=0.002$; Fig. 1A) or specifically versus RSV-A infections $(\mathrm{p}=0.009$; Fig. 1B).

We also compared nitrate levels between single versus co-infections and found that they were not significantly different from the no virus detected group (Table 2). The concentration of NW nitrate was higher in the co-infection group, although it was not significantly different even when only those specimens were analyzed in which nitrate was detectable (Table 2). 

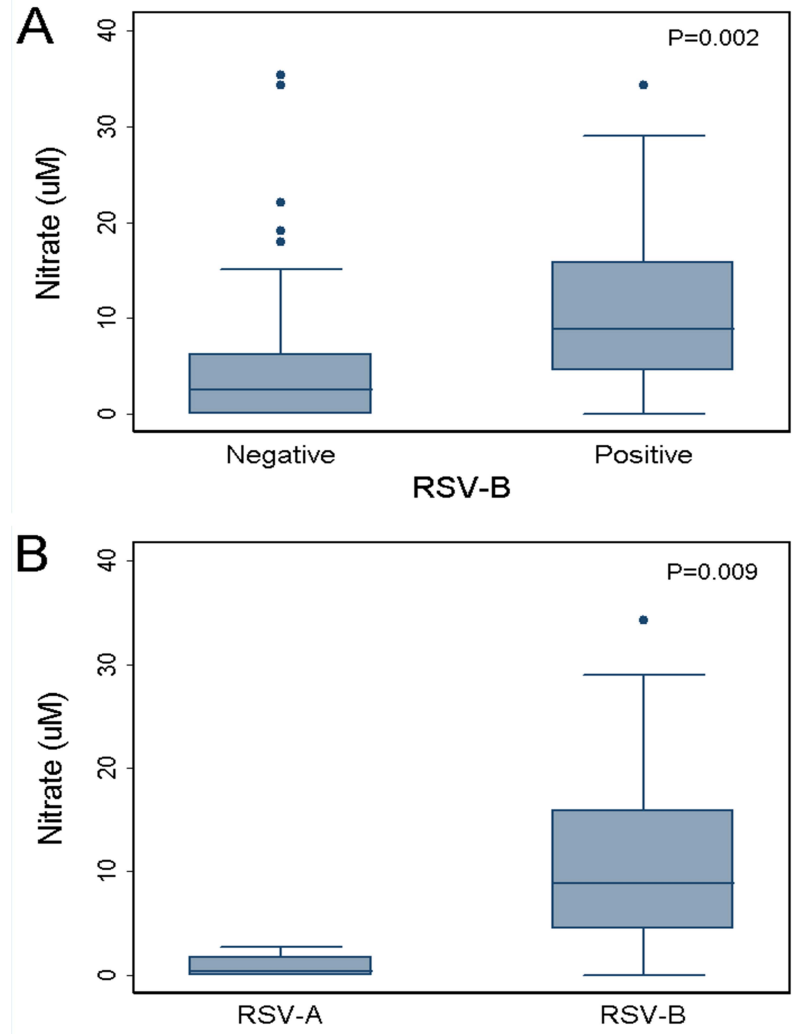

Fig. (1). Nasal wash nitrate in children with and without RSV subtype B-mediated influenza-like illness presenting to the emergency department during the 2009 influenza pandemic. Data include single as well as co-infections. (A) RSV-B positive $v s$ RSVB negative; (B) RSV-B positive vs RSV-A positive. The box depicts the range of values between the $25^{\text {th }}$ and $75^{\text {th }}$ percentiles with a line showing the median; whiskers encompass the adjacent values within 1.5 interquartile range of the nearer quartile.

We explored if NW nitrate level was higher in children with more severe ILI. The median nitrate concentration was 7.8 $\mu \mathrm{M}$ (IQR 3.1-15.8) for hospitalized children and 4.9 $\mu \mathrm{M}$ (IQR 2.9-10.3) for children discharged from the ED; this was not significantly different $(\mathrm{p}=0.533$ by Mann-Whitney $U$ Test).

\subsection{Specimens with Detectable IgA and IgG}

We expected to detect a virus in at least $80 \%$ of children who were enrolled in the study using real time PCR. To

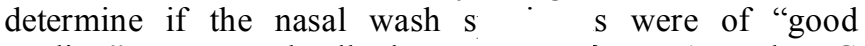
quality," we tested all the sampıes for $\operatorname{IgA}$ and $\operatorname{IgG}$ immunogloublins. Twenty seven $(30.7 \%)$ of the 88 nasal wash specimens we tested did not have detectable IgA or IgG immunoglobulins. We then compared the percentage with virus detected in the "good quality" versus "poor quality" nasal wash specimens: $50(82 \%)$ of 61 good quality specimens versus $10(37 \%)$ of 27 poor quality specimens were positive for one or more viruses (chi-square; $p<$ $0.001)$.

Nasal wash samples with detectable immunoglobulins were significantly more likely (RR 2.2; 95\% CI: 1.34-3.67) of having a virus detected compared to nasal wash samples with non-detectable IgA or IgG immunoglobulins. Because of this significant difference in detecting a virus in "good" versus "poor" quality nasal wash specimens, an ad hoc analysis was conducted with only specimens considered of good quality.

In Table 1, the distribution of IgA positive samples by ILI groups (nH1N1 virus positive, non-nH1N1 virus positive, and no virus detected) is presented with no significant difference in distribution. Table $\mathbf{2}$ describes the distribution of IgA positive samples by number of viral pathogens detected (single viral infection, co-viral infection, and no virus detected groups) and again there was no significant difference between groups.

When only those subjects with detectable IgA and IgG in their nasal wash specimen was analyzed we found no significant differences in age, gender, ethnicity or clinical outcomes (Table 3). Furthermore, NW nitrate concentration, overall as well as when analyzing only specimens in which it was detectable, was not significantly different between the groups (Table $\mathbf{3}$ ).

\section{DISCUSSION}

The current study is the first of its kind to demonstrate potential utility of NW nitrate and nitrite analyses in pediatric patients with ILI presenting to the ED. Overall, nitrite levels were very low, while nitrate was detectable in the majority of patients with ILI. These data are consistent with other studies suggesting that nitrate is the predominant NO metabolite in the respiratory tract $[10,15]$, hence that may explain why nitrate, and not nitrite, in nasal secretions is the more readily detectable of the two. Both nitrite and nitrate are stable in aqueous solutions at neutral $\mathrm{pH}$, thus the lower concentration of nitrite was not due to lesser stability. Furthermore, a study by Grasemann et al. showed that nitrate was higher in bronchoalveolar lavage (BAL) fluid from children with pneumonia, and that there was a significant correlation between plasma and BAL nitrate [10].

Studies have shown a direct correlation and similarity between the composition of the upper airway secretions, as measured in nasal specimens, and the lower respiratory tract fluid, as determined by bronchoalveolar lavage [24]. Given the relative ease with which upper respiratory secretions can be collected from children, it provided us the rationale for studying NOx in nasal lavage. Nasal secretions contain multiple proteins, some of which play an important role in host defense owing to their antimicrobial potential. We can speculate that proteins like lactoferrin or other metalloprotiens, found in nasal secretions, may be utilizing nitrite as a substrate for NO production and this may be part of the antimicrobial activity of nasal secretions. This may also explain why nitrite is low in them. Future studies can analyze the above proteins to assess whether they are increased or to assess their nitrite reductase potential in vitro. The utilization of nitrite as a substrate for NO production may account for some of the anti-microbial actions of the host.

The current study was not set up to obtain blood from the enrolled patients. One way to demonstrate that a more aggressive immune response can be causative for the elevated nitrate in NW, could be by assessing correlation between the nitrate and peripheral blood white cell counts. 
Table 3. Demographic Characteristics, Clinical Outcomes and Nasal Wash Nitrate Between Subjects with ILI Infected with Novel (n) H1N1, Other Viruses, or with No Virus Detected, at the TCH ED During the 2009 nH1N1 Pandemic. Only Specimens with Detectable IgA and IgG are Included in the Analysis

\begin{tabular}{|c|c|c|c|c|}
\hline & Total N=61 (\%) & $\begin{array}{c}\text { nH1N1 Virus } \\
\text { Positive n=11 (\%) }\end{array}$ & $\begin{array}{l}\text { Non-nH1N1 Virus } \\
\text { Positive } n=39(\%)\end{array}$ & $\begin{array}{c}\text { No Virus Detected } \\
n=11(\%)\end{array}$ \\
\hline Age in Months: Median (IQR) & $12(6-41)$ & $47(7-76)$ & $11(5-20)$ & $60(9-115)$ \\
\hline \multicolumn{5}{|l|}{ Gender } \\
\hline Male & $36(59 \%)$ & $6(54 \%)$ & $24(61 \%)$ & $6(54 \%)$ \\
\hline Hispanic & $40(66 \%)$ & $10(91 \%)$ & $27(69 \%)$ & $3(27 \%)$ \\
\hline Non-Hispanic & $21(34 \%)$ & $1(9 \%)$ & $12(31 \%)$ & $8(73 \%)$ \\
\hline Black & 2 & 0 & 2 & 0 \\
\hline White & 12 & 0 & 6 & 6 \\
\hline Hospitalized & $10(16 \%)$ & $0(0 \%)$ & $8(21 \%)$ & $2(18 \%)$ \\
\hline Hours in ED: Median (IQR) ${ }^{+}$ & $3.5(2.3-5.1)$ & $3.5(2.3-5.1)$ & $3.5(2.6-5.5)$ & $3.8(1.6-6.8)$ \\
\hline Supplemental Oxygen & $3(5 \%)$ & $0(0 \%)$ & $2(5 \%)$ & $1(9 \%)$ \\
\hline Hours of Oxygen: Median (IQR) & NA & NA & NA & NA \\
\hline Intravenous Fluids (IVF) & $8(13 \%)$ & $0(0 \%)$ & $6(15 \%)$ & $2(18 \%)$ \\
\hline Hours of IVF: Median (IQR) & $26.2(5.9-38.1)$ & NA & $3.5(2.6-5.5)$ & NA \\
\hline Healthcare visit after discharge & $10(17 \%)$ & $2(18 \%)$ & $6(15 \%)$ & $2(18 \%)$ \\
\hline \multicolumn{5}{|l|}{ Nasal Wash Nitrate } \\
\hline
\end{tabular}

${ }^{\mathrm{T}}$ For patients discharged home from the ED.

*For all samples ( $\mathrm{p}=0.57$ by Kruskal-Wallis Test).

** For samples with detectable nitrate ( $\mathrm{p}=0.476$ by Kruskal-Wallis Test).

Nasal wash nitrate concentration in children with ILI was comparable among the children infected with nH1N1 compared to children infected with other respiratory viruses combined or those for whom a virus was not detected. Similarly, children with single viral infection versus co-viral infection versus those with no detectable viral agent had comparable illness outcomes and nitrate levels in their nasal wash samples. We were unable to address whether NO or its metabolites could be used to gauge severity of disease. This was most likely due to an insufficient number of children who were hospitalized for comparison. Although not statistically significant, nitrate concentration in hospitalized children was nearly twice that of non-hospitalized children. This might be of clinical relevance; adequately powered prospective studies will address this better. Additional studies with large numbers of non-hospitalized and hospitalized children presenting with an acute respiratory illness will be needed to determine if NW nitrate is a reliable biomarker for disease severity and can be used to complement clinical assessment.

The higher concentration of NW nitrate in children with RSV versus non-RSV in general, was more marked when the analysis was done for RSV subtypes. This is consistent with studies that have demonstrated a robust generation of $\mathrm{NO}$ as part of an innate immune response to RSV [5]. Albeit, our patient population was highly selective for ILI based on CDC guidelines, the respiratory pathogenesis due to RSV may explain the higher concentration of NW nitrate in this subgroup. The small numbers of RSV subtypes preclude a detailed assessment of the differential levels of nitrate when comparing A versus B, we can speculate that the B subtype is more pathogenic and thus caused the higher concentration of NW nitrate.

Exhaled NO has been studied as a putative biomarker for respiratory infections caused by influenza, rhinovirus and other viral pathogens [19-21], but the data have been 
equivocal. The conflicting data above may simply reflect technical issues in measuring exhaled NO. This methodology is cumbersome to achieve in the pediatric population, either in the in-patient or the ED settings. Thus, the strength of our study was that we focused on stable NO metabolites in nasal secretions. Additionally, NW specimens are easy to perform and readily accessible from children with acute respiratory illness such as the population of children we studied who presented to the ED with ILI. Early diagnosis of influenza facilitates initiation of antiviral therapy that may decrease morbidity, mortality, and secondary spread within the household. However, currently available rapid diagnostic assays for influenza are insensitive and false negative results may provide undeserved reassurance to clinicians $[25,26]$. As such, elevated levels of NO metabolites in respiratory samples may provide sensitive, albeit nonspecific, evidence of viral etiologies.

Our study had several limitations. The pilot cohort was relatively small and given the lack of severe ILI observed, we were unable to detect statistically significant correlations between NW NO metabolites nitrate and nitrite and important patient outcomes. An adequately powered prospective study might demonstrate statistical significance. In the future, we will conduct power calculations to ascertain what " $n$ " values are needed to reach statistically significant differences.

Nitrate was undetectable in several samples. The normal saline used for the nasal wash was free of nitrite and nitrate. The absence of nitrate may be due to low volumes of nasal secretions in those particular patients or the volume of saline used to collect may have diluted the sample to below the detection limit of the HPLC (1nM). However, since we used the same volume of saline for each wash in each patient, whatever the reason for the undetectable levels of nitrate is reflective of that particular patient. Table 2 shows the proportion of samples with detectable nitrate. The median and ranges are calculated by utilizing the values from the samples with detectable levels. Statistical comparisons should not be affected since we applied non-parametric tests.

The presence of IgA or IgG in nasal wash was used to indicate a "good quality" specimen, based on prior experience [23]. In approximately $30 \%$ of the children, the nasal wash specimen was considered "poor quality" based on Ig levels (data not shown). However, when only those subjects with detectable $\operatorname{IgA}$ and $\operatorname{IgG}$ in their nasal wash specimen were analyzed we found no significant differences in age, gender, ethnicity or clinical outcomes. Furthermore, NW nitrate concentration, overall as well as when analyzing only specimens in which it was detectable, was not significantly different between the groups. Hence, it was unlikely to be confounding our results; however, highlighting this observation will hopefully provide a tool to other investigators to evaluate the quality of the nasal wash specimen which is not done in most clinical trials.

\section{CONCLUSIONS}

Overall, this is an early demonstration for the potential of NW nitrate as a biomarker for acute respiratory viral infections in children presenting to the ED. An adequately powered prospective study in the ED, conducted during the respiratory viral seasons (fall, winter and spring), having good quality NW specimens, and enrolling larger numbers of acutely ill children with a wide range of illness severity will be required to fully ascertain if NW levels of nitrate can predict important clinical outcomes.

\section{CONFLICT OF INTEREST}

The authors confirm that this article content has no conflicts of interest.

\section{ACKNOWLEDGEMENTS}

AIM and FL acknowledge the Thrasher Research Fund for Early Career Awards (NR-0058 \& NR-0097, respectively). The study sponsors had no role in the study design, data collection/analysis, writing or submitting the manuscript. We also acknowlede Nathan S. Bryan, at the University of Texas-Houston Health Science Center, for his support in nasal wash nitrite and nitrate analyses.

\section{REFERENCES}

[1] Peiris JS, Poon LL, Guan Y. Emergence of a novel swine-origin influenza A virus (S-OIV) H1N1 virus in humans. J Clin Virol 2009; 45(3): 169-73.

[2] Melendi GA, Laham FR, Monsalvo AC, et al. Cytokine profiles in the respiratory tract during primary infection with human metapneumovirus, respiratory syncytial virus, or influenza virus in infants. Pediatrics 2007; 120(2): e410-5.

[3] Szretter KJ, Gangappa1 S, Lu X, et al. Role of host cytokine responses in the pathogenesis of avian $\mathrm{H} 5 \mathrm{~N} 1$ influenza viruses in mice. J Virol 2007; 81(6): 2736-44.

[4] de Jong MD, Simmons CP, Thanh TT, et al. Fatal outcome of human influenza A (H5N1) is associated with high viral load and hypercytokinemia. Nat Med 2006; 12(10): 1203-7.

[5] Stark JM, Khan AM, Chiappetta CL, et al. Immune and functional role of nitric oxide in a mouse model of respiratory syncytial virus infection. J Infect Dis 2005; 191(3): 387-95.

[6] Karupiah G, Chen JH, Mahalingam S, Nathan CF, MacMicking JD. Rapid interferon gamma-dependent clearance of influenza A virus and protection from consolidating pneumonitis in nitric oxide synthase 2-deficient mice. J Exp Med 1998; 188(8): 1541-6.

[7] Akaike T, Noguchi Y, Ijiri S, et al. Pathogenesis of influenza virusinduced pneumonia: involvement of both nitric oxide and oxygen radicals. Proc Natl Acad Sci USA 1996; 93(6): 2448-53.

[8] Akaike T, Okamoto S, Sawa T, et al. 8-nitroguanosine formation in viral pneumonia and its implication for pathogenesis. Proc Natl Acad Sci USA 2003; 100(2): 685-90.

[9] Nevin BJ, Broadley KJ. Nitric oxide in respiratory diseases. Pharmacol Ther 2002; 95(3): 259-93.

[10] Grasemann H, Ioannidis I, de Groot H, Ratjen F. Metabolites of nitric oxide in the lower respiratory tract of children. Eur J Pediatr 1997; 156(7): 575-8.

[11] Alving K, Weitzberg E, Lundberg JM. Increased amount of nitric oxide in exhaled air of asthmatics. Eur Respir J 1993; 6(9): 136870 .

[12] Kharitonov SA, Wells AU, O'Connor BJ, et al. Elevated levels of exhaled nitric oxide in bronchiectasis. Am J Respir Crit Care Med 1995; 151(6): 1889-93.

[13] Kharitonov SA, Yates D, Barnes PJ. Increased nitric oxide in exhaled air of normal human subjects with upper respiratory tract infections. Eur Respir J 1995; 8(2): 295-7.

[14] Kharitonov SA, Yates D, Robbins RA, et al. Increased nitric oxide in exhaled air of asthmatic patients. Lancet 1994; 343(8890): 1335.

[15] Gaston B, Drazen JM, Loscalzo J, et al. The biology of nitrogen oxides in the airways. Am J Respir Crit Care Med1994; 149(2 Pt 1): 538-51.

[16] 2009-2010 influenza season triage algorithm for children $(\leq 18$ years) with influenza-like illness. Available from: http://www.cdc. gov/h1n1 flu/clinicians/pdf/childalg orithm2.pdf

[17] Bennett BL, Garofalo RP, Cron SG, et al. Immunopathogenesis of respiratory syncytial virus bronchiolitis. J Infect Dis 2007; 195(10): $1532-40$. 
[18] Bryan NS, Grisham MB. Methods to detect nitric oxide and its metabolites in biological samples. Free Radic Biol Med 2007; 43(5): 645-57.

[19] de Gouw HW, Grünberg K, Schot R, Kroes AC, Dick EC, Sterk PJ. Relationship between exhaled nitric oxide and airway hyperresponsiveness following experimental rhinovirus infection in asthmatic subjects. Eur Respir J 1998; 11(1): 126-32.

[20] Murphy AW, Platts-Mills TA, Lobo M, Hayden F. Respiratory nitric oxide levels in experimental human influenza. Chest 1998; 114(2): 452-6.

[21] Sanders SP, Proud D, Permutt S, Siekierski ES, Yachechko R, Liu MC. Role of nasal nitric oxide in the resolution of experimental rhinovirus infection. J Allergy Clin Immunol 2004; 113(4): 697702.

[22] Laham FL, Trott AA, Bennett BL, et al. Lactate dehydrogenase concentration in nasal-wash fluid is inversely associated with disease severity in children with bronchiolitis presenting to the emergency department. Pediatrics 2010; 125: e225-e33.

[23] Munoz FM, Piedra PA, Glezen WP. Safety and immunogenicity of respiratory syncytial virus purified fusion protein-2 vaccine in pregnant women. Vaccine 2003; 21: 3465-7.

[24] Mosser AG, Vrtis R, Burchell L, et al. Quantitative and qualitative analysis of rhinovirus infection in bronchial tissues. Am J Respir Crit Care Med 2005; 171(6): 645-51.

[25] Hurt AC, Alexander R, Hibbert J, Deed N, Barr IG. Performance of six influenza rapid tests in detecting human influenza in clinical specimens. J Clin Virol 2007; 39: 132-5.

[26] Cruz AT, Demmler-Harrison GJ, Caviness AC, Buffone GJ, Revell PA. Performance of a rapid influenza test in children during the H1N1 2009 influenza a outbreak. Pediatrics 2010; 125(3): e645-50.

Received: June 19, 2012

Revised: September 7, 2012

Accepted: September 11, 2012

(C) Mian et al.; Licensee Bentham Open.

This is an open access article licensed under the terms of the Creative Commons Attribution Non-Commercial License (http://creativecommons.org/licenses/by-nc/3.0/) which permits unrestricted, non-commercial use, distribution and reproduction in any medium, provided the work is properly cited. 